DOI: $10.5216 /$ racs.v6.66387

\title{
La interculturalidad en el proyecto educativo de Macedonia: consideraciones acerca de la educación indígena en el Amazonas
}

\section{Charles Brito ${ }^{1}$}

\section{RESUMEN}

El artículo reflexiona sobre la interculturalidad en el Proyecto Educativo Comunitario de la Institución educativa Francisco de Orellana, en la comunidad Ticuna ribereña de Macedonia (Departamento de Amazonas, Colombia). Las referencias teóricas son las de interculturalidad crítica y la descolonialidad. El abordaje del campo fue etnográfico, desarrollado con jóvenes, adultos y maestros, a través de entrevistas, cuestionarios y observaciones de diarios de campo. Como conclusión, el artículo enfatiza que la interculturalidad tiene una cualidad sustantiva que facilita las relaciones con el estamento, una cuyo agregado hace que la escuela parezca un enclave occidental. Sin embargo, la interculturalidad, en su perspectiva crítica, puede revertir la situación, ya que ayuda a que la escuela se dé cuenta de sus capacidades para interculturalizar desde la práctica pedagógica, permitiendo así, enriquecer una educación propia desde la cual es posible el equilibrio de saberes.

PALABRAS ClAVES: Descolonialidad. Interculturalidad. Educación indígena. Ticuna. Pensamiento indígena.

\section{Interculturalidade no projeto educativo da Macedônia: considerações sobre a educação indígena na Amazônia}

\section{RESUMO}

O artigo reflete sobre a interculturalidade no Projeto Político Pedagógico da Escola Francisco de Orellana na comunidade ribeirinha Ticuna de Macedônia (Departamento do Amazonas, Colômbia). As referências teóricas são as de interculturalidade crítica e descoloniedade. A abordagem do campo foi etnográfica, sendo desenvolvida com jovens, adultos e professores, por meio de entrevistas, questionários e observações em diários de campo. Concluindo, o artigo enfatiza que a interculturalidade tem uma qualidade substantiva que facilita as relações com órgãos do governo, uma vez que faz a escola parecer uma ancora do Ocidente. No entanto, a interculturalidade, em sua perspectiva crítica, pode reverter a situação, pois ajuda a escola a revisar suas habilidades de interculturalidade a partir da prática pedagógica, possibilitando assim, uma educação própria enriquecida, desde a qual o equilíbrio de saberes seja possível.

\footnotetext{
${ }^{1}$ Río Grande do Sul (UFRGS), Porto Alegre, Río Grande de Sul, Brasil. Brasil. E-mail: charlesbritto662@gmail.com.
} 
PALAVRAS-CHAVE: Descoloniedade. Interculturalidade. Educação Escolar Indígena. Tikuna. Pensamento indígena.

Interculturality in the Macedonian educational project: considerations about indigenous education in the Amazon

\begin{abstract}
The article reflects about the interculturality in the Community Educational Project carried out in the educational institution Francisco de Orellana located in the riverside Ticuna community of Macedonia (Amazon state, Colombia). Theoretical references are about the critic interculturality and the decolonization. The field approach was ethnographic, developed with the young people, adults and teachers through interviews, questionnaires and daily field observations. As a conclusion, the article emphasizes that the interculture skills have a substantive quality that facilitates the statement relationship and make the school looks like a western enclave. However, interculturality, in a critic perspective, can reverse the situation since it helps the school to realize its capacities to interculturize from pedagogical practice, allowing to enrich their own education from which the equilibrium of knowledge is possible.
\end{abstract}

KEY WORDS: Decolonization. Interculturality. Indigenous Education. Ticuna. Indigenous thought

\title{
Introducción: La pedagogía intercultural en el Francisco de Orellana
}

La institución educativa Francisco de Orellana en el Resguardo Indígena Ticuna de Macedonia, Departamento del Amazonas, Colombia, un lugar próximo a la frontera con Brasil y Perú, guarda un especial interés por el concepto de la interculturalidad, a punto que se vale de el para gestionar la relación distante (y a veces tirante) que sostiene con las agencias gubernamentales que supervisan su funcionamiento. Estas mismas agencias que reciben diferentes nombres a lo largo de la historia, han hecho negativa a los requerimientos y gestiones que vienen desde la comunidad en materia educativa, algo que ya les sucedió al comienzo con Monseñor Marceliano Canyes, cuando administraba la educación del Departamento, y a quien tuvieron que insistirle mucho para que aprobara la fundación de su escuela primaria en 1974.

Sin embargo, en 2011, luego de décadas de escolaridad, siete comunidades indígenas además de Macedonia (Puerto Triunfo, La libertad, Zaragoza, Vergel, Mocagua, Palmeras, San Martin de Amacayacu), habían madurado sus pretensiones en materia educativa y querían tener un bachillerato en su propio territorio. Ya no dependían enteramente de las agencias estatales, sino de su capacidad de entender el SEIP, como es conocido el Sistema de Educación Indígena Propia, un modelo pedagógico y de gestión que les brinda a las 
instituciones educativas indígenas de Colombia la autonomía para determinar su rumbo. Fue así que estas comunidades se reunieron en Macedonia para organizar el Proyecto Educativo Comunitario (PEC) de la sede Francisco de Orellana (que ya había iniciado con cursos de secundaria desde 2007), al cual titularon: "Formación y desarrollo desde las prácticas culturales y ancestrales ticuna, yagua, kokama, huitoto, en el marco de las relaciones interculturales"

El complemento del título del proyecto educativo es fundamentalmente importante: "En el marco de las relaciones interculturales". En últimas, porque, aunque se espera que la escuela indígena sea un lugar en el que la comunidad prepara a su sociedad para mejores relaciones con la modernidad, esto no significa que la escuela (como un reflejo de occidente) absorba por completo al indígena, ya que, en gran medida, como dice Kusch (2007), el indígena tiene la capacidad de fagocitar lo occidental ${ }^{2}$. Esto conlleva a decir que hay una doble condición en las escuelas interculturales que hacen las veces de frontera entre lo indígena y lo no indígena, la cual hace que se les vea como enclaves occidentales (GASCHÉ, 2010) o bien, como injertos indígenas (BERGAMASCHI, 2005). Una situación ambigua, porque incluso la más convencida de las escuelas indígenas puede ser enclave de civilización en la medida que gran parte de las rutinas remedan una escuela convencional, por ejemplo, con sus horarios, clases segmentadas y los modelos administrativos, que necesariamente tienen que implementar para sacar adelante la gestión documental.

Paradójicamente a este último aspecto, se debe, para el caso del proyecto educativo de Macedonia, que buena parte del $P E C$ se encuentre más ocupado en parecer intercultural que en serlo. Las ocho menciones a la interculturalidad que hay en el escrito de trescientas páginas del Francisco de Orellana, tienen la enunciada función de soportar legal y académicamente el proyecto. Circunstancia similar que se presenta con las otras trece menciones sobre lo intercultural, con las cuales se busca enfatizar por medio del sustantivo, que no se trata de un proyecto exclusivo "de y para" ticunas, sino de uno que respeta las participaciones interétnicas, pues cabe mencionar que, aunque los Resguardos Indígenas del proyecto son predominantemente Ticuna, son ante todo comunidades multiétnicas (como también lo menciona el titulo). Visto así, la interculturalidad es la palabra "clave" (chave en

\footnotetext{
${ }^{2}$ En palabras de Kusch (2007, p 179) "Pero como ya venimos encarando el problema desde otro ángulo, podemos afirmar que la aculturación se produce solo en un plano material, como la arquitectura o la vestimenta, en cambio en otros ordenes, pudo haberse producido un proceso inverso, diríamos una fagocitación de lo blanco por el indígena".
} 
portugués) que ayuda a que la comunidad despeje las dudas de propios y extraños, pues al ser del orden intercultural el proyecto "funciona como debe funcionar".

Ya sea tomada como término o enfoque, lo cierto es que, con su inclusión en el título, la interculturalidad como sustantivo consigue apaciguar la tensión interadministrativa que hay por lo educativo entre ellos y los agentes estatales supervisores, y vuelve a funcionar nuevamente cuando aparece a lo largo del texto para enfatizar el ánimo colaborador y multiétnico del proyecto; un aspecto importante al interior de la organización. Pero es justamente debido a esa comprensión meramente sustantiva del concepto, que al menos en lo documental, los contrasentidos saltan a la vista. Por ejemplo, en el adjunto del PEC titulado "Principios Orientadores a partir de Nuestras Cosmovisiones-Principios Unificadores" (CODEBA, 2011, p.45), un documento que, como su nombre lo indica, consiste en que todas las etnias del proyecto escolar presentan un resumen de su cosmovisión con la intención de participar en condiciones de equidad, se observa una discrepancia con otro documento fundamental del colegio: El plan de estudios. Al revisar este último, se puede ver que la interculturalidad promovida en el adjunto contrasta con la inclusión de la asignatura Lengua Materna Ticuna, una materia que se da a todos los estudiantes del colegio, si bien no todos lo son, puesto que en 2011 el censo del Proyecto registraba hablantes 59\% ticunas, 27\% yaguas, 13\% cocamas (CODEBA, 2011). Este tipo de contradicciones que confunden lo multicultural con lo intercultural son un recordatorio de cuán cerca se encuentra la escuela de seguir siendo un enclave de occidente, aunque esté convencida de lo contrario.

Pero, así como la escuela indígena puede ser enclave, también es injerto de lo que se vive en la comunidad y el mundo exterior, porque como piensa Bergamaschi (2005) su papel en la configuración de las escuelas es más activo de lo que se cree, ya que siempre el sentir y deseo comunitario acaba por absorber las formalidades de la escolaridad convencional. Opera, metafóricamente hablando, como un injerto en el que siempre permanece la fuerza de la raíz que la germinó: Na força local que a nutrirá, e sobretudo, manterá o modo próprio de ser (BERGAMASCHI, 2005, p.320). Esto es verdad inclusive en ese aspecto documental en el que brillan las contradicciones, por lo que en el proyecto educativo Francisco de Orellana también se pueden encontrar esfuerzos por navegar exitosamente en la convencionalidad desde comprensiones propias. Se puede ver por ejemplo en el Plan de Estudios y simbología para Preescolar, Básica Primaria, secundaria y media vocacional, que el colegio quiso explicar mediante metáforas del pensamiento Ticuna, la progresión psicopedagógica (al mejor 
estilo constructivista piagetiano) que el estudiante debe ir alcanzando a medida que avanza en el proyecto escolar (ver tabla 1). En Quinto grado el estudiante aprende que la vida se parece al bejuco; en grado Sexto valora su propia inteligencia indígena representada en la corona de plumas, en todo lo que significa hacerla y tenerla, y aprende también a valorar el conocimiento que se encuentra en los libros. Y finalmente, en los grados Décimo y Once, encaran el ciclo de media vocacional mediante la metáfora de la tinaja y el frutero, que representa bien la relación que hay entre el énfasis del colegio (proyectos productivos) y la vocación artesanal de la comunidad.

Tabla 1 - Metáforas/lineamiento para la enseñanza propia en el Francisco de Orellana

\begin{tabular}{ll}
\hline GRADO & METAFORA/LINEAMIENTO CURRICULAR \\
\hline PREESCOLAR & El bejuco como inicio para la construcción del canasto \\
$1^{\circ}$ & La base del canasto \\
$2^{\circ}$ & La forma del canasto \\
$3^{\circ}$ & El cimiento del canasto \\
$4^{\circ}$ & La estructura del canasto \\
$5^{\circ}$ & El canasto terminado \\
$6^{\circ}$ & La corona y el libro \\
$7^{\circ}$ & El delfín \\
$8^{\circ}$ & El pensador \\
$9^{\circ}$ & La canoa, el remo, el niño y el agua \\
$10^{\circ}$ & La tinaja \\
$11^{\circ}$ & El frutero \\
\hline
\end{tabular}

Fuente: Brito (2018).

En contraste a ese aspecto ambiguo que es lo documental, el proyecto en la práctica pedagógica es claro y sobre todo consciente de lo que quiere. En ese campo la educación intercultural indígena es más que nada injerto (en el sentido de Bergamaschi), pues la preocupación principal es la de enseñar desde lo propio, aunque en el camino tengan que irse acomodando a las convenciones. Por añadidura esto significa, que las imperfecciones textuales que aparecen con frecuencia cuando se revisan los documentos de los proyectos 
educativos, y que hacen ver erráticas las propuestas de colegios que se promocionan a sí mismos como interculturales, tienen un margen de interpretación a favor. Al menos en el caso del Francisco de Orellana, estos contrasentidos se justifican al revisar la historia de la instalación de la secundaria, la cual es inicialmente producto del trabajo de Macedonia, al que luego se fueron sumando las demás comunidades interesadas a partir de 2011. Y la inclusión de la asignatura de Lengua Materna Ticuna y el uso de metáforas Ticuna, que dan la impresión de ser una pauta hegemónica que no contempla a los otros pueblos indígenas con los que comparte proyecto, en realidad pueden leerse como parte de los esfuerzos iniciales que se hicieron por traducir y proyectar al formato euro-centrado, una diversidad étnica que en el plano práctico fue aumentando después de que plantearan el proyecto, y que no ha sido objeto de reflexión y actualización. Al fin de cuentas las fisuras en la coherencia interna del documento pueden reacomodarse, pues finalmente no se trata solamente del deber ser de la interculturalidad registrado allí, intentando ser impoluto de contradicciones. Se trata, para estar de acuerdo con Fornet Betancourt, de ser éticamente interculturales y de hacer interculturalidad en la práctica cotidiana: "Hay que compartir vida, memoria histórica e, incluso, proyectos [...] Crear una cultura de la comunicación contextual no es simplemente una cuestión de información por imágenes o, si se quiere, mediática" (ASOCIACIÓN ALEMANA, 2004, p.27).

En consecuencia, la práctica pedagógica del Francisco de Orellana es generosa y permite ver la urgencia por presentar iniciativas que trasluzcan interconocimientos, los cuales revelan su capacidad de asimilar lo ajeno desde una plataforma que tiene su propia manera de pensar, idear y actuar. La mayoría de los proyectos que se han venido adjuntando al PEC desde 2011 (ver tabla 2), los mismos que se acumulan a manera de anexos y que le dan esa aura enciclopédica de trescientas páginas que tanto aprecian en la escuela, se planearon para hacerse al aire libre, fuera del salón, con adultos que no siempre son profesores y con la expresa intención de desencuadrar al joven de su rol de estudiante, sacarlo del confinamiento de tiempos/espacios que puede llegar a ser la escolaridad convencional. Parafraseando a Gasché "desde luego, la dominación de la sociedad nacional condiciona mas no determina" (GASCHÉ, 2010, p.112). Y por eso la evolución y las motivaciones de los agentes que intervienen en la realidad educativa conformada por indígenas y no indígenas, por profesores y no profesores, siempre guardan la capacidad de manifestar en la práctica, la decisión 
personal sobre la pauta dominante. Veremos algo de esta emancipación pedagógica en la última sección del artículo.

Tabla 2 - Proyectos Propios del Francisco de Orellana llevados a cabo desde 2011

\section{Nombre del proyecto}

1 Proyecto ambiental escolar mariposas

2 Proyecto de investigación de la quebrada kuyaté

3 Proyecto: Club de ciencias discípulos del sabio Metare

4 Proyecto de recuperación y reforestación de plantas maderables y comestibles

5 Proyecto: Normas de convivencia y leyes de origen; La salud sexual y reproductiva a partir de las caracterizaciones sobre nuestro ciclo de vida

6 Proyecto: El legado ancestral de artistas talladores

7 Proyecto: Aprendo a producir textos orales y escritos a través de cuentos, mitos y leyendas.

8 Proyecto: Conviértase en sabio a través del conocimiento ancestral.

Fuente: Brito (2018).

Finalmente, aunque se le busque más que nada por su utilidad para terciar en controversias, sigue habiendo en la interculturalidad un trasfondo de inconformidad que tiene que ver con su naturaleza conflictiva. Eventualmente, lo intercultural, tanto en lo práctico como en lo teórico, y esto especialmente en el campo educativo, plantea lo que formulara Panikar (1996); es decir, que se le entienda como un campo de batalla en el que constantemente hay discusión por ver quién tiene la razón y con ello una guerra por obtener la prevalencia de su sistema de verdad; o bien, que se le entienda como una tierra de nadie en la medida en que no abundan los diálogos sino los monólogos interesados en reafirmarse a sí mismos ignorando al otro. La sede principal Francisco de Orellana, amplia y sin muros, con andenes peatonales que la atraviesan, una escuela expuesta a todos y todas las subjetividades de la comunidad indígena de Macedonia, parece reflejar este último punto de vista. Y por eso, cuando profesores, estudiantes y acudientes opinan sobre lo que pasa en ella, acaban 
exhibiendo pensamientos distintos (como es natural), pero además dando la impresión de que entre ellos hay un abismo o mínimo, un vacío intercultural que no logran conectar.

\section{La ambigüedad intercultural en lo escolar}

El campo del trabajo para conocer la escuela, el proyecto educativo, y reconocer la interculturalidad que circula allí, ocupó los meses de enero, septiembre, octubre y noviembre de 2017 y enero de 2018. En ese tiempo se obtuvieron las entrevistas, relatos y observaciones con profesores, adultos y jóvenes, que sirvieron de base para artículos como el presente. Algunos extractos de las entrevistas se han mencionado y mencionan más adelante, y parte de lo que sigue corresponde a unas encuestas aplicadas a diecisiete profesores y cuarenta estudiantes de la secundaria del Francisco de Orellana a finales de noviembre de 2017. Los extractos destacados de estas encuestas se organizaron en las tablas que siguen a continuación, buscando plantear aquel vacío que hay entre unos y otros. Revisándolas, se reconoce la carencia del puente comunicacional, dando la impresión de que no se trata únicamente de una falta de voluntad de dialogar, sino de "un para qué dialogar". Esta es en sí la crisis del enfoque intercultural, pues nos muestra que no basta con pretender hacer uso de la interculturalidad sin antes comprender mejor qué es lo que se entiende por interculturalidad, o por lo menos tener la capacidad de darse cuenta cuándo se está haciendo, o no, uso de ella.

Al respecto, se ha tomado como referencia a Walsh (2009) para decir que la interculturalidad comprende tres perspectivas. La primera perspectiva es la relacional, la que hace referencia a la "forma más básica y general al contacto e intercambio entre culturas, es decir, entre personas, prácticas, saberes, valores y tradiciones culturales distintas" (p.2). La segunda se puede denominar funcional, porque "se enraíza en el reconocimiento de la diversidad y diferencias culturales, con metas a la inclusión de la misma al interior de la estructura social establecida" (p.4). En ella se busca la solución, se proponen los ánimos reparadores y conciliadores, pero no se toca el problema, no se le critica y se le da por superado. Ya se han presentado aquí muestras de esta interculturalidad funcional, por ejemplo, en el uso sustantivo de la palabra a lo largo del documento. La tercera perspectiva es la crítica, porque según Walls (2009) "no partimos del problema de la diversidad o diferencia 
en sí, sino del problema estructural-colonial-racial” (p.4). En una perspectiva crítica de la interculturalidad se llevan las relaciones establecidas al punto de inflexión en el que se evidencia (o no) una hegemonía del saber, poder y ser que se impone a otra, lo cual significa identificar las desigualdades o disparidades que se generan por una exclusión del saber del otro cultural. En esta concepción de la interculturalidad queda entreabierta la posibilidad de inferir lo que hay de intercultural en una expresión. No quiere decir que para acceder a ello deba hacerse un análisis profundo de la psicología social de los jóvenes y profesores, más bien consiste en una interpretación mejor intencionada de las palabras. Y es a partir de dicha posibilidad de interpretación que vale la pena tomar las respuestas y observaciones registradas.

\subsection{Colegial juventud indígena}

Desde que inauguraron el primer grado sexto en 2007, la comunidad indígena de Macedonia percibió que los conflictos juveniles de su colegio eran similares a los de los muchachos que se iban a estudiar en los colegios de Leticia o Puerto Nariño, las ciudades más cercanas. Se decía que entre los jóvenes circulaba con fuerza el desinterés por conocer sus prácticas culturales y un desgano por hacer parte de las labores tradicionales, y en su lugar, crecía el entusiasmo por imitar los modos, lenguajes y maneras de la ciudad. La situación entonces, hizo pensar a los adultos de la comunidad, que los estudiantes de la secundaria de Macedonia querían precisamente un colegio no indígena, y obviamente no estaban de acuerdo con eso. También hay que decir, que, en esos primeros momentos de construcción del proyecto, aunque los adultos (profesores, adultos y abuelos) tenían claro que debían escuchar la mayor cantidad de puntos de vista posibles, fue muy poco lo que se tuvo en cuenta la participación de la juventud estudiantil. Su participación fue tímida, limitada a aprobar las iniciativas de una comunidad preocupada con la perdida cultural de tradiciones, que veía en su escuela la única manera de recuperarse. En correspondencia, desde el punto de vista adulto, los jóvenes altamente influenciados por la modernidad son poco capaces de discernir la importancia de lo propio, lo cual preocupa mucho a la comunidad.

No obstante, en las respuestas de los cuestionarios y en los diálogos, la crítica puede darse sin hacerse explicita hasta porque, como explica Kusch (2007), lo que se piensa de conceptos abstractos como la interculturalidad, representan en sí mismos un plano inconsciente del pensamiento comunitario que hay que escudriñar (ver tabla 3). Por ejemplo, 
en la frase de la estudiante "me gustaría que la escuela fuera como una universidad muy bonita", lo bonito de la escuela podría no referirse a lo estrictamente estético, es decir, a dar por bonita una escuela cerrada con muros; y en cambio, puede ser el modo que la joven encontró para tensionar una realidad propia, la de su escuela en mal estado, sin mantenimiento y sin recursos tecnológicos. En otra encuesta un joven comentó que le pesa no ir a la escuela, porque cuando eso sucede se ve obligado a dedicarse a trabajos que son para él aburridos (refiriéndose a tareas tradicionales como cultivar o sembrar) "porque uno esta abajo el sol tumbando palo para poder sacar alimento de la chagra como por ejemplo la fariña". Y a continuación dijo: "pero en parte uno es feliz porque recibe la educación de sus padres". Allí, en el instante en que se va convenciendo de que la escuela es menos aburrida que la vida familiar; y al mismo tiempo divaga de su convicción porque nota "algo valioso en lo cultural", este joven en particular, exhibe una postura crítica de la escolaridad, aunque no se percate del hecho. Pedagógicamente hablando, dilemas como este constituyen momentos significativos de aprendizaje, que son propicios para que el profesor tensione lo intercultural más allá de la comprensión superficial, pero como se concluye adelante, dicho cierre no siempre acontece o simplemente se omite.

Tabla 3 - Respuestas de los jóvenes acerca de la interculturalidad y la Educación Propia

\section{\# Proyección de la Escuela Apropiación de la cultura Por fuera de la escuela en respecto a Otra escuela diferenciándose de la relación con su cultura Otra}

1 Mi escuela ideal sería como la de la Normal Superior que sea cerrada de dos pisos [...] tendría computadores, una emisora, con internet tendría canchas.

2 Mi escuela ideal es Inem porque me gusta aprender lo que ellos hacen.

\begin{tabular}{|c|c|}
\hline $\begin{array}{l}\text { No quiero olvidar nuestras } \\
\text { costumbres todo lo que } \\
\text { hacemos como cazar } \\
\text { sembrar frutas vegetales y } \\
\text { también los juegos } \\
\text { autóctonos. }\end{array}$ & $\begin{array}{l}\text { La familia es normal, hablan } \\
\text { en lengua materna, hacemos } \\
\text { actividades como hacer asaí, } \\
\text { asamos pescado y arrancamos } \\
\text { yuca, participo de las } \\
\text { actividades de danza y tiro de } \\
\text { arco y flecha, la pucuna y } \\
\text { canotaje }\end{array}$ \\
\hline
\end{tabular}

[...] quisiera nunca Pues sería dedicarse los olvidarme de mi cultura trabajos, pero sería muy porque no me importa el aburrido, porque uno esta dinero y solo me importa abajo el sol tumbando palo la vida de Dios porque para poder sacar alimento de Dios cuesta más que el la chagra como por ejemplo la fariña. Pero en una parte uno 
dinero.

es feliz por que recibe también la educación de los padres.

3 Me gustaría que la escuela fuera como una universidad muy bonita y que tenga aire acondicionado en las aulas.
No tengo dinero, pero quiero a mi cultura, soy ticuna, como pirarucú y otras cosas. [...]cuando no estoy en la escuela me pasan cosas malas porque mi cultura dice, que nosotros tenemos que estudiar para ser alguien en la vida.

Fuente: Brito (2018).

Otras respuestas no necesitan inferirse, ya que son completamente explicitas, especialmente en las que la juventud prospecta su colegio. Según lo dicho, ellos quieren que se parezca a la Escuela Normal Superior (ENS), a un campus universitario o un Inem, referencias escolares que tienen de Leticia tanto por su estructura física como por lo que entienden son modelos pedagógicos a imitar. Esto equivale a decir que los jóvenes, además de manifestarse insatisfechos por la infraestructura desvencijada de su colegio, acusan cierta responsabilidad de sus profesores en la baja calidad de su educación, juzgándolos especialmente por la pérdida de clases durante los Paros. En este orden de ideas, la preocupación inicial de los adultos según la cual la juventud asiste a la escuela con la obsesión de la ciudad en su mente, causando un total desinterés por lo propio, debiera considerar comentarios como los de la tabla 3 (en lo que respecta a la apropiación cultural) y también el comportamiento observado en los jóvenes durante los periodos de Paro escolar, momentos en los que era de esperarse, no hubo un retorno automático de ellos a las rutinas familiares. Hay que tener en cuenta que actuaban como si estuviesen en una jornada normal de clases sin clases, por lo que era poco probable que los estudiantes ayudaran en la casa, simplemente porque cuando normalmente llegaban del colegio, los deberes del hogar ya se habían hecho.

En esos días de "clase sin clase", los estudiantes ocuparon su tiempo "libre" escuchando música, haciendo deporte y tareas, nadando, pescando o elaborando artesanía, labores consecuentes con la rutina de estudiantes que viven normalmente, lo cual no supone que hayan abandonado aspectos como la tradición y sus prácticas culturales, ya que de hecho se trata de un asunto que aprecian (algo que les gusta). Lo que se advirtió en los diálogos con los jóvenes, en esos momentos de crisis escolar, es que se encuentran expectantes de las 
mejoras que van a suceder al retomar las clases (en estructura y en lo que entienden es pedagogía), y que, desde luego, cuando no se dan, lo toman como una promesa incumplida que le resta confianza en su colegio. De este modo concluyen que la escuela falla en su misión de formarlos como sujetos capaces de desenvolverse en la desigualdad social, pues así como en tiempos antiguos la escuela permitió a sus padres alcanzar dignidad al enfrentar el analfabetismo castellano, hoy en día los jóvenes exigen niveles de formación en materia de lenguajes y tecnologías similares a los de las escuelas convencionales, que les permitan enfrentar las distancias abismales que hay entre ellos y cualquier otro joven de Leticia o del mundo.

Es más, puede que parezca una divergencia de opinión con raíces intergeneracionales, como afirma Paladino (2006), en el que, para el caso de los jóvenes, la secundaria ya no es el fin del ciclo escolar sino una fase previa a la profesionalización técnica o universitaria, un tema que para los adultos acaba siendo de menor relevancia. Pero esto no indica que sea únicamente la juventud la que piensa la comunidad y la ciudad en términos de una relación simbiótica, en la que la primera es el presente, la segunda el futuro y la escuela el tránsito entre ambas facetas, sino que se trata de una cuestión ineludible para todos. Para el caso particular de Macedonia, si bien la fórmula la han aprendido en la escuela, la televisión o la internet, todo indica que esta preocupación por relacionarse bien con lo occidental ha sido resultado de la vivencia diaria de recibir extranjeros en el complejo turístico de tres malocas, y desde luego, también debido a los reiterativos mensajes que reciben de los padres, pastores y profesores, en las casas, escuelas y cultos, acerca de lo imperativo que es profesionalizarse y ser alguien en la vida. Participando en un diálogo juvenil, uno de los jóvenes tensionaba el tema de la identidad frente a las relaciones interculturales diciendo: "Es que no se deja de ser indio por la forma sino por el abandono del pensamiento", "ser de ojos claros o aprender tecnología, no te hace menos Ticuna” (BRITO, 2018).

En efecto, lo intercultural es una preocupación permanente del joven y no necesariamente su participación es pasiva; hay que ser optimistas y decir que de manera inteligente y versátil buscan la consolidación de su propia identidad en medio de este dilema social de ser y no ser indígena. Por fuera de la escuela se pudo verificar que los reclamos por no tener salones pulcros, internet rápido, computadores y tabletas nuevas, (respuestas que aparecieron intensamente en las encuestas) no influyen negativamente en su relación con la tradición. En cambio, se observa una especie de indianía que circula intensa en estos espacios 
de socialización (BRITO, 2018) ${ }^{3}$, la cual parece suficiente para seguir orgullosos de sus raíces, aunque no tanto como sus padres y profesores anhelan. La música que escuchan los jóvenes en sus celulares (el rap, la salsa, el forró, la cumbia peruana, el vallenato, el reggaetón) por lo general tienen también versiones Ticuna (letra, melodía y canto). En la intimidad de las casas visitadas o en los corrillos en que se reúnen en su tiempo libre para jugar o "estarse no más", se habla lengua materna (o se hace el intento). Este tipo de comportamiento social y juvenil es mucho más apreciable en las festividades comunitarias de tamaño importante como las que se tuvieron para celebrar el aniversario de Macedonia el 12 de octubre; la misma fecha en que se celebra el día de la raza, los macedonios celebran su fundación. Allí los jóvenes fueron los más activos, haciendo parte del concurso de baile tradicional, el cual incluía reinado y ensayos de coreografías que se repetían hasta la media noche, en un ejercicio muy diferente al que hacen cuando bailan para turistas o para las visitas ocasionales que llegan al colegio. En definitiva, como planteara Brandão (1995), la educación en su vuelo más libre, es una fracción de toda una experiencia cultural en la que "há relações entre pessoas e intenções de ensinar-e-aprender. (p.8). Así, a medida que las costumbres circulan en la cotidianidad, la comunidad juvenil crea campos educativos sin horarios, paredes y profesores titulados.

El joven busca y crea sus propios espacios porque los necesita para renovar lo que ya ha aprendido de su cultura, pero la comunicación fluida que debiera dialogar esos saberes juveniles a una escala intergeneracional (o sea con los adultos y profesores) se ausenta, y en cambio, muchas de las ambivalencias se procesan en soledad, en soliloquios singulares y ambiguos. Singulares porque a diferencia de sus profesores y padres, mucho de la era digital les es inherente, natural y urgente. Ambivalente, porque esa experiencia en la colonialidad que los impulsa a querer saber y hacer lo "no indígena", también los frustra al percibir que su escuela intercultural es más indígena que lo que debiera ser, "sin muros y coliseos". Y finalmente ambigua, porque al mismo tiempo que se le exige al joven que asista al colegio para ser alguien mejor que sus padres, se le critica también por no ser como ellos, dejando la idea de que la única vía para ser indígena es la adulta, negando de esta manera la posibilidad de una actualización de su indianía que parta de su propia experiencia.

\footnotetext{
${ }^{3}$ Indianía, es "esa" emergencia psicológica y espiritual que la persona construye, mientras identifica en su actuar/pensar, maneras de sentir y pensar propias de lo indígena, y que además le permiten (o no), adherirse a la historia cultural del pueblo, a su mítica como interpretación del mundo. Brito (2018).
} 


\subsection{La docencia en disputa}

La nómina de cincuenta y cuatro docentes (el total de profesores del proyecto) hace su vida en las comunidades en que enseñan. Una mayor proporción comparte una formación pedagógica normalista, convencional y constructivista. Aproximadamente una cuarta parte es nativa de las comunidades del proyecto, aunque no todos enseñan en aquellas en que nacieron. Otra mitad que no es nativa, es mayoritariamente amazonense, nacidos en Leticia, Puerto Nariño, y el norte del Departamento. Algunos profesores llegaron y se quedaron, y al día de hoy tienen hijos, familia, negocios y vivienda. Finalmente, una última y pequeña proporción viene del centro del país. Aquellos profesores que a la fecha no tienen ningún tipo de arraigo, viven en arriendo, en habitaciones y casas de las comunidades, o en las mismas escuelas, varias de las cuales aún conservan las alas especiales de vivienda que la Educación Contratada de Monseñor tenía para sus docentes. Los profesores son queridos y parte activa de la vida social de las comunidades, van de pesca, lideran acciones comunitarias, participan en eventos sociales y deportivos, recorren el rio de aquí para allá en el bote escolar, van y vienen de Leticia o Puerto Nariño, sea para cobrar el salario mensual, visitar familiares y amigos o simplemente para cambiar de aire y así manejar el stress.

Retomando lo referido por Walls (2009), se puede decir que las reservadas opiniones que los profesores dieron en las encuestas señalan una comprensión de la interculturalidad del tipo funcional, aunque se presuman críticas. En buena medida parecen revelar la influencia de algún tipo de marco conceptual que globalmente dicta "el debe ser" de la interculturalidad, principalmente como enfoque de gestión política, que a lo largo de los años ha resultado conflictivo, en especial para las comunidades. Según Walls (2009), puesto que a lo largo de las décadas el concepto fue asumiendo un sentido socio-estatal de burocratización basado en la legitimación de "derecho étnico y colectivo" (respaldado por la firma del Convenio 169 de la OIT), la interculturalidad llegó a ser parte del aparato de control y de la política educativa estatal, gracias a que muchas organizaciones y comunidades indígenas influenciaron en lo que en principio se siente fue una victoria. Pero en la práctica este avance también les hizo perder confianza en ella, ya que, tras el reconocimiento merecido, entró en juego la subsecuente instalación de mecanismos de regulación y el posterior debilitamiento de lo propio.

En las encuestas, esta influencia de un marco global y conflictivo que supedita las opiniones sobre lo intercultural, alcanza a reflejarse en el hecho de que los profesores mezclan las referencias personales con otras generales. Y por eso, porque no pueden escapar de este 
marco general y ambiguo, los profesores a pesar de que el ejercicio de hacer las encuestas no fue ligero y para ellos llevó un prudente tiempo de reflexión, acaban asegurando con convencimiento que "una escuela intercultural se hace a medida que nos transformemos e integramos la globalidad a nuestra gente”, y también que crean que lo intercultural consiste en "respetar las costumbres de otros y apropiarse de algo que me va a servir en la vida", o que finalmente le teman y que por eso consideren necesario "capacitar bien al estudiante para cuidarse de los peligros de la interculturalidad". "Globalidad, Otredad, ética, transformación, integración, capacidad, apropiación" resultan ser nociones que se exteriorizan en las respuestas porque acompañan bien a la interculturalidad como retórica, mas no como reflexión. Probablemente la última frase, aquella de "los peligros de la interculturalidad", resuma la percepción general respecto al concepto: La docencia en general se encuentra claramente prevenida con la interculturalidad promovida desde el estamento.

Tabla 4 - Respuestas de los docentes acerca de la interculturalidad y la educación indígena

\begin{tabular}{llrl}
\hline \# Qué se entiende por & Qué características propias le \\
escuela & indígena \\
intercultural & & $\begin{array}{l}\text { Quétos ven para la } \\
\text { educación intercultural }\end{array}$
\end{tabular}

1 Una escuela indígena, una Se encuentra en la trasmisión El reto más importante escuela intercultural se de conocimientos que son es poder adaptar nuestro hacen a medida que nos semejantes en su contexto aun pensamiento a la transformemos e sin embargo diferentes en su integremos la globalidad a conceptualización. nuestra gente. globalización y esta unificación de la educación.

2 Valorar la identidad El carácter propio de la La educación propia del cultural para poder educación del ticuna se indígena hay que defenderla ante la encuentra en el diario vivir. Se valorarla en los colegios, interculturalidad. diferencia con la otra solo en teniendo maestros las lenguas. formados en el campo lingüístico ticuna. 
3 De lo intercultural es que Los huitotos tienen su tradición

Primero el personal tenemos que respetar las y cultura vivas y los cocamas tiene que estar costumbres de otros y ya las están perdiendo. preparado en diferentes apropiarse de algo que me va a servir en la vida. áreas del conocimiento sin dejar de lado las tecnologías.

Fuente: Brito (2018).

Las opiniones interculturalmente funcionales han jugado en contra de la perspectiva crítica de la interculturalidad, y con ello es comprensible que se haya reforzado entre la comunidad educativa la creencia de que el enfoque intercultural es una tendencia momentánea que cederá con la aparición de un nuevo término académico que la releve. Pero esta comprensión logra que se pierda de vista el valor de los esfuerzos autónomos, por ejemplo, en las maniobras tácticas que los macedonios hacen por medio de su PEC y en las iniciativas pedagógicas en las que se puede comprobar que los profesores y la comunidad general no actúan hegemónicamente sino de forma intercultural (en el sentido de Fornet Betancourt). Hay registros al respecto. Barbosa (2006), cuenta cómo en una ocasión la escuela programó una pelazón como evento cultural para recibir una comisión del Ministerio de Educación, y al ser cuestionados por un pastor de Bogotá acerca de la actividad, respondieron que era necesario hacer dichos eventos para no perder la condición de indígenas ante el Estado (p.126). Y Brito (2018) describe lo que sucede cuando los Ticunas reciben a los turistas en el complejo de malocas, un momento en el que, igual que en la escuela, hacen una presentación cultural de la pelazón, de lunes a domingo y hasta cinco veces por día: "Mientras el hombre explica el rito a los turistas, las mujeres del baile seleccionan del grupo una joven blanca para llevarla a trastienda y vestirla de "moça nova" (p. 57). Luego de la presentación cultural en que la "moça nova" es blanca, una joven turista aindiada dijo: "Las mujeres ticuna me retiraron del grupo y me vistieron así, sentí nervios, no sabía cómo actuar con la mirada de todos los turistas encima de mí" (BRITO, 2018, p.57). En los casos de Barbosa y Brito hay una diferencia importante con el acostumbrado manejo que las agencias turísticas le dan a las expresiones culturales de los indígenas. Aquí se deja ver un tratamiento intercultural, 
ya no solamente funcional sino crítico, que constituye un vuelco sutil al enfoque preponderante que viene desde el indígena (y su intelectualidad) como proponente. Lo que aflora en esas ocasiones en que son ellos los proponentes, es por decirlo de alguna manera, un pensamiento social y comunitario, activo y "fagocitador" de lo occidental, desde el cual actúan como bloque, porque, aunque retóricamente se puede criticar la interculturalidad, en la práctica se debe ser críticamente interculturales, sobre todo cuando se trata de mantener buenas relaciones con aliados estratégicos para la comunidad.

Un último factor que interviene en que los docentes no puedan comprender la interculturalidad como un enfoque critico (teórico, político y práctico), tiene que ver con la formación convencionalmente normalista de la mayoría de sus profesores, la cual también interfiere en que se den cuenta de aquellos momentos en los que hacen aproximaciones reflexivas acerca de su modelo pedagógico intercultural. Cuando el profesor Ticuna dice: "aqui no se practica mucho la interculturalidad, casi no sabemos nada de las otras etnias, únicamente en lo que nos parecemos, eso es lo que se aprovecha para enseñar”, está señalando precisamente la importancia de reconocer el diálogo de saberes en equidad, pues ¿qué sentido tiene enseñar sobre las semejanzas sin pasar por apreciar las diferencias? Y más aún, ¿qué sentido tiene darles a las semejanzas un valor positivo y a las diferencias uno negativo?, como casi siempre implica decir "en lo que nos parecemos", sino es el de reafirmar que el parámetro de saber válido (el que sirve) es el propio y no el ajeno. En el fondo, la reflexión del profesor es entre el gremio docente un secreto a voces: Las críticas interculturales en los ambientes escolares indígenas fluyen duramente y con cierta comodidad cuando se trata de occidente, pero definitivamente no es igual cuando tienen que fijarse en el tratamiento que le dan a la propia diversidad de su escuela, una en la que, por ejemplo, los Ticuna comparten espacio y saberes con otros pueblos indígenas.

En esto consiste la disputa del docente. En lo que pasa con el profesor en aquellos momentos en que, posiblemente afectado por un repertorio global que dicta lo que es la interculturalidad, insiste en actuar como embajador de la civilización, en tanto que, por otro lado, la práctica docente lo pone al frente de un campo de enseñanza en el que se piensa en varias lenguas. Esa misma docencia despierta en la mañana concentrada en su misión de civilizar, inherente a la formación docente; y a medio día, sino es que antes, termina rendida a las circunstancias únicas que los reta a que enseñen lo que vinieron a enseñar. Sin embargo, para poder seguir, el docente sabe que tiene que intentar otra manera, es decir, la manera del 
otro, un paso difícil de dar porque inválida el propio saber como parámetro de verdad. En definitiva, si hay un agente en esta cadena educativa al que le cuesta la descolonización del saber, este es principalmente el profesor de la escuela intercultural.

\subsection{La comunidad pendiente}

Los adultos de Macedonia recuerdan con cariño su escuela, a pesar de las condiciones adversas en las que estudiaron. El profesor Mariano (ahora Rector del colegio), anotaría que en la antigua escuela se estudiaba todo el día, alternativa que se tomaba para poder nivelar a los niños lo antes posible, pues siendo tan solo dos profesores, separarlos por cursos y jornadas, era lo menos inteligente que se podía hacer. En esas épocas en la que los adultos de hoy eran niños, muchos remaban el rio para llegar a clases y sus padres hacían lo mismo hasta Puerto Nariño para comprar los útiles escolares. Matusalén, un artesano de la comunidad, contó en entrevista que empezó a estudiar ya grande y con la intención de aprender a escribir su nombre, "Yo me recuerdo que llevaba mi cuaderno en una bolsita de azúcar amarrado con una soguita, a veces iba con zapato o sin zapato, pantalón, pantaloneta, tenía uniforme pero mis amigos no" (Entrevista a Matusalén, 29 de noviembre 2017).

Por esta raigambre comunitaria en que la escuela significó parte importante de la vida de los adultos, es que la comunidad cuestiona severamente al colegio, a sus profesores y estudiantes. Un padre de familia, a propósito de los días en que no se pudo traer los jóvenes de las otras comunidades al Francisco de Orellana porque no había gasolina para el motor del bote, criticaba que tampoco se les dio clases a los jóvenes de Macedonia mediante la siguiente reflexión: "nada se aprende sin constancia y no se entiende por qué los jóvenes de aquí no están en la escuela en este momento, si todos los profesores del colegio viven aquí [...] el buen profesor es el que debe atraer al estudiante con su ejemplo y creatividad, pero qué le puede enseñar el profesor al joven sobre entrega al estudio, si él mismo no muestra iniciativa y compromiso y en cambio entra en Paro por falta de gasolina" (Entrevista TC, 29 de noviembre de 2017). En el mismo sentido, pero esta vez refiriéndose a una actitud despreocupada de los jóvenes, Matusalén señaló: "Si el colegio estuviera aquí cerquita como lo está de ustedes, ya yo estaría enseñando mi dialecto o enseñando otras cosas, estaría ahí ocupado y no como ustedes ahí perdiendo tiempo, porque no se ocupan en nada, como no hay ocupación y pierden tiempo” (Entrevista a Matusalén, 29 de noviembre 2017). 
Estas exigencias, que parten de insatisfacciones de la comunidad que se encuentra muy pendiente de lo que se hace en la escuela, tienen todo sentido puesto que, si han apostado tanto en el colegio, es porque quieren hacer de los jóvenes el futuro inmediato de Macedonia. Pero desde luego, esos padres que critican a los profesores por su poca capacidad de motivar el aprendizaje y a los estudiantes por su apatía a la escuela, no alcanzan a darse cuenta de que envían diariamente a sus hijos a un lugar que recrea una rutina escolar, que, con sus horarios, recesos y vacaciones, se parece en todo a cualquier trabajo de la ciudad y no a la vida de un indígena en su comunidad. En esas circunstancias, como se dijo antes, es contradictorio esperar que sean los jóvenes los que tomen la iniciativa de hacer las tareas de la casa, que se preocupen por aprender de los abuelos, y que sean más adultos, como lo eran sus mayores a la edad de quince años.

Ciertamente hay una brecha a la que le hace falta un puente, que no es otra cosa que el diálogo entre acudientes, profesores y estudiantes. De todos modos, de momento, estando de acuerdo con lo que sucede o no, en las comunidades cada integrante a su manera pone de su parte para que el proyecto salga adelante. Los profesores, pese a las limitantes de recursos (teóricos, técnicos, didácticos y tecnológicos), trabajan para llevar a cabo iniciativas menos ortodoxas, ya que sospechan que en lo intercultural hay una alternativa. Los acudientes, que recuerdan con amor la antigua escuela, aunque dan por sentado que los jóvenes no los escuchan, tampoco dejan de surtir al ambiente de indianía, con consejos, prácticas culturales y lenguas. Y los estudiantes, jóvenes indígenas de la modernidad, resuelven lo intercultural entre anhelos y frustraciones, configurando su propia indianidad; una que tiene que seguir su propio camino.

\section{La interculturalidad en la comunidad Yagua de la Libertad}

Chaumeil (1994) opinaba que los Yagua en el Alto Amazonas, lejos de encontrarse en un callejón sin salida, "se insertaron durante siglos en un vasto corredor de intercambios abiertos al exterior" (p.184). Sin embargo, la presencia de yaguas en el contexto regional se percibe intrusa, impropia, y desafortunadamente hoy en día son más recordados por algunos 
experimentos comerciales que se hicieron con ellos y que remedan los zoológicos humanos del siglo $\mathrm{XIX}^{4}$.

La escuela Nuestra Señora de la Paz en la comunidad Yagua de la Libertad, una de las ocho sedes del proyecto educativo comunitario del Francisco de Orellana, brinda educación básica primaria a ochenta niños, por medio de cuatro docentes, dos de ellos ticunas, y dos más que se reconocen a sí mismos como mestizos. La escuela cuenta con una sección de salones para clase, una vivienda de profesores, y una sala de alimentación donde se sirven las meriendas de los programas estatales para la alimentación de la primera infancia (menores de 6 años) y también los almuerzos del programa Departamental de alimentación escolar. Se le preguntó a uno de los profesores Ticuna que enseña en la sede Nuestra Señora de la Paz de la comunidad de La Libertad: ¿Y cómo te va siendo Ticuna entre Yaguas?

\begin{abstract}
Toca utilizar el castellano para enseñar, para relacionarme y preguntar a las personas mayores por cuestiones culturales como algunos mitos, formas de trabajo [...] Son muy diferentes, pero algunas cosas tienen similitud por ejemplo la bebida [se refiere al masato]. Pero en su existencia son diferentes a los ticunas. Nosotros nos basamos en la pesca, en la chagra, y ellos, ellos son más cazadores, la cacería, la pesca a veces, pero no son buenos pescando. En la escuela hasta ahora estamos integrando niños y costumbres. Por ejemplo, con la actividad que siempre hacemos. Buscamos esa parte cultural de la pesca para que los niños tengan esa posibilidad, también para aprender a pescar artesanalmente más que todo el anzuelo y las varas en los diferentes lugares, las quebraditas que hay por ahî" (Entrevista Profesor Ticuna).
\end{abstract}

El "Día de la pesca Rosa Linda" es una actividad anual que los profesores idearon con el objetivo de presentar una escolarización comprometida con la comunidad y su futuro. Rosa Linda, fue una estudiante a la que le gustaba mucho pescar, incluso habiendo clase; y que, en un día lamentable para todos, fallece víctima de un alud que le cae encima en momentos en que pescaba a orillas del rio Amazonas. El día de la pesca que lleva su nombre es una de las varias experiencias educativas interculturales que los profesores del Francisco de Orellana realizan, que no se encuentra consignada en el documento PEC, y que, además, a diferencia de las vistas en la tabla 2, parte de la posición Yagua.

En 2017 el "Día de la Pesca Rosa Linda” iba en su tercera versión. Ese día en la mañana, los profesores reunieron a los niños en una formación general para darles las instrucciones de la actividad. Los estudiantes pequeños para la edad, son fuertes, tímidos y muy obedientes. Fueron llegando poco a poco, y algunos descalzos, con las manos sucias de

\footnotetext{
${ }^{4}$ La isla de los micos en la década del ochenta del siglo XX, ofrecía en su paquete turístico visitas guiadas a una aldea Yagua intencionalmente puesta sobre la margen de un tributario del Amazonas. Estas familias indígenas traídas desde el Perú, con el paso del tiempo se dispersarían a lugares como la Libertad.
} 
tierra, daban la impresión de no haberse cambiado de ropa desde el día anterior. Las reglas que les dieron para la jornada fueron precisas: jamás pueden ir solos a pescar, mínimo tienen que estar en parejas; únicamente se acepta la pesca con barandilla, nada de redes; pueden elegir entre pescar en las quebradas o en el rio Amazonas; no se puede pescar antes del toque de campana que abre la jornada y tampoco después del que la cierre. Luego de la formación siguió la oración que uno de los profesores dirigió. Mientras sucedía, los niños observaban a sus profesores, nada más.

Este día de la pesca no va a ser muy bueno porque el rio está creciendo y no hay abundancia. Además, la manera de motivar a los niños es teniéndoles los anzuelos listos y en esta ocasión no pudimos hacerlo por la reunión de ayer en el colegio. No obstante, los niños están animados, llegaron mucho antes que la jornada escolar comenzara. (Entrevista Profesor Noe, septiembre 2017dem).

Al acabar la pesca, un poco más allá del mediodía, los profesores juntaron todas las sartas que los niños atraparon y las extendieron sobre hojas de plátano, mientras que los padres y madres de familia iban acercándose con la intención de comprar la producción del día. Los profesores habían preparado jugos para recibirlos y además una ceremonia de premiación de la actividad. Allí se tomaron los pesos, las tallas, y se premiaron la sarta más bonita, la más grande, la más pequeña, la más numerosa; el pescado más difícil de pescar, el más grande, el más pequeño; el pescador más grande, el más pequeño. Tantas categorías de premiación fueron la excusa inventada por los profesores para poder entregarle a cada niño uno de los obsequios que les habían comprado (de su propio bolsillo) el fin de semana en Leticia. Había entre los premios, juguetes, camisetas, pantalonetas, muñecas y balones, pero la mayoría eran recipientes para comida, colores, cuadernos, anzuelos de pescar y carretes de nylon. Los portacomidas son importantes porque, como explicó la profesora Casilda, los niños los usan para llevar comida para la casa, lo cual es un lujo y una muestra de lo "adultos" que son los niños indígenas.

Después de la actividad no hubo una clase aparte en la que los profesores enseñaron los derivados académicos de ir a pescar, por ejemplo, para aprovechar a contar números, medir longitudes, etc. El proceso de enseñanza-aprendizaje sobrevino en la pesca misma, y como es obvio ahora, en un intercambio mutuo de profesor a estudiante. Los grupos de niños que se dispersaron entre quebradas y el rio para pescar, reproducían una educación propia: la Yagua. Ensimismarse en el ejercicio de armar la barandilla y elegir los potenciales lugares de pesca, les permitió practicar la lengua tranquilamente, ya que al no tener que explicar 
pequeñeces de la pesca a un "no yagua", pudieron dedicarse por completo a la ciencia de medir la corriente, la profundidad y el comportamiento de la especie, a capturarlos según el agua en la que nadan. Observándolos al detalle, se pudo notar que acumular la cantidad suficiente para ganar el concurso pasaba a segundo plano, simplemente podían equivocarse y volver a intentarlo; y podían también, acertar y cansarse de sacar pescados del mismo lugar. Mientras los niños Yagua demostraban e intercambiaban sus saberes en una actividad cotidiana, a los profesores les pasaba lo que a ellos en la formación: se quedaron callados, observando, aprendiendo de la diferencia, sacando sus propias conclusiones desde su saber ticuna y mestizo, respectivamente (no despectivamente).

\footnotetext{
Usted se dio cuenta son pequeñitos en compañía de otros más pequeñitos. Lo que les gusta es pescar, ese es su pasatiempo y son muy buenos en ello, no se van a achantar si no pica un pescado los primeros diez minutos [...] Se dará cuenta que casi no hablan entre ellos, que apenas y se hacen gestos para cambiar la carnada y que en la elección del lugar hay casi un arte, una ciencia que les hace ir exactamente donde se encuentra el pescado que les gusta o el que más fácil se deja pescar. Uno termina dándose cuenta lo habilidosos y tenaces que son para efectuar tareas que les gustan. Se funden tanto con la selva que se despreocupan de sí mismos. Viera usted lo que se sufre enseñándoles lo del aseo diario (Entrevista profesor Lionel, septiembre 2017).
}

Por lo expuesto, alguien puede pensar que el aprendizaje que se da a partir de las experiencias interculturales se reduce a una enseñanza meramente orgánica. Pero no necesariamente es así. Lo cierto es que de cada experiencia sensible que el docente tiene con sus niños, surge primero un saber pedagógico cuyo objetivo principal es traducir al saber indígena lo que el profesor considera "saber universal", y esto le pasa incluso al mismo profesor indígena. De allí que cuando los profesores de la libertad se reúnen con sus colegas de las otras sedes del proyecto, insisten permanentemente en lo indispensable que es hacer sus propios didácticos ajustados a la geocultura tan diferente que viven, que sirvan especialmente para la enseñanza de la lectura, la escritura y las operaciones aritméticas básicas. Pero por lo general, en esas mismas reuniones se pone sobre la mesa el tema de los libros que envía el Ministerio de Educación Nacional y que muy poco se usan en las escuelas, argumento que finalmente aplaca los reclamos de falta de inversión como los que hacen los profesores de la Libertad. En realidad, el reclamo no se hace por algún tipo de desobediencia gremial, sino porque los docentes son conscientes de que día tras día desde que comienza el año, van sintiendo que se quedan atrás de las expectativas de los niños con los que no se logran entender. 
En ese orden de ideas, a pesar de que los profesores de la escuela Nuestra Señora de la Paz no han iniciado una producción intensa de material didáctico propio, si han entendido que, al aprender de prácticas culturales tan diferentes a las suyas, ellos, los Yagua y el PEC, dieron un paso importante por la educación propia de La Libertad. Sin embargo, ha sido difícil el paso principal de transmitir a la comunidad el valor de la escolaridad, ya que, pese al tiempo transcurrido entre ellos, los niños y la comunidad en general siguen viendo en los profesores y la escuela una cuestión distante. Según un padre de familia entrevistado el asunto no cala porque: "es que por más que se esfuercen por hacer la escuela atractiva, no van a entender que somos gente que no le encuentra el sentido a estudiar”. (BRITO, 2018). Así visto, las vacaciones de semana santa, octubre, mitad y de final de año, lo mismo que las repetidas interrupciones por Paros nacionales y las constantes reuniones de trabajo que se hacen casi semanalmente y por las cuales pierden clases, aumentan la sensación de que la Escuela se encuentra allí porque toca y no porque quiera, y por eso, aunque puedan tolerarla, los de la Libertad no terminan de confiar completamente en ella.

En ese ambiente de desconfianza intercultural, poco pueden hacer los profesores para saldar las cuentas que el Estado tiene con el pueblo Yagua colombiano; son impotentes. Pero las claves para contrarrestar el desinterés de la comunidad por la escuela se encuentran en la misma queja, y como dijo otro profesor, en este camino hay dos alternativas: La primera requiere la fórmula poco probable de una escuela que nunca detenga sus actividades, que tenga sus propios profesores yaguas, y que funcione de lunes a domingo, de enero a diciembre. Y la segunda, ya la hemos visto aquí, consiste en promover una educación simpática que involucre a los habitantes y los niños mediante prácticas educativas que asimilan y son asimiladas por las prácticas culturales propias Yagua. El profesor Ticuna de la escuela amplía esta idea:

Aquí, por ejemplo, con solo dar una ojeada ya se habrá dado cuenta el recelo con
que los niños y los adultos lo ven, no solo a usted, a nosotros también y eso que
llevamos en promedio seis años de permanencia. Los niños se esconden cuando ven
gente diferente y la experiencia nos ha demostrado que solo pasando mucho tiempo
con ellos vencen su timidez y empiezan a mostrar su carácter, en ese sentido no son
gente de arrojar todas las cartas en una sola partida, se guardan las suyas sin
importar si la mano les es ventajosa. Al principio la comunicación era totalmente
nula, ellos hablando entre sí en su idioma mientras nosotros cebábamos con
carteleras, rondas y tableros llenos de letras con frases en castellano (Entrevista
profesor Lionel, septiembre 2017).

En el fondo esta "alergia" a la escuela y a los profesores quizás tenga que ver con lo que en conjunto representa el Estado para la Libertad: una herida colonial (MIGNOLO, 2015, 
p.85). Aún hoy en día la comunidad indígena de la Libertad cuya fundación significó para los Yagua emanciparse del montaje turístico que los explotaba, no tiene la calidad de Resguardo indígena como la mayoría de las comunidades ribereñas, y por eso depende del Resguardo indígena vecino de Zaragoza para recibir parte de las trasferencias económicas a las que tiene derecho por parte del Estado. No se trata de un asunto menor, por lo que iniciativas como las del "día de la Pesca Rosa Linda", que son clara y deliberadamente encaminadas por el "menos palabra y más hacer”, interculturalmente prácticos en el sentido de Gasché (2010), mitigan, alivian, aproximan y ayudan a que la comunidad sea más tolerante con la escolaridad que ofrece el PEC del Francisco de Orellana.

En el "Día de la Pesca Rosa Linda" hay un progreso psicopedagógico significativo del proyecto educativo Francisco de Orellana, pues este modo de instrumentalizar la interculturalidad, propone un modo de cortar la secuencia histórica de escuelas indígenas del tipo "enclave occidental", propiciando la vivencia de una escuela del tipo "injerto". Los profesores de la escuela Nuestra Señora de la Paz, admitiendo que hacen parte de un esquema convencional de pedagogía, optan en cambio, por darle al día de la pesca el lugar principal entre todas las iniciativas que han implementado para insertarse definitivamente en la comunidad, reconociendo eso sí, que la experiencia tiene un peso académico que aún no logran calcular; un paso profesional enorme para cada uno de ellos. Y, por otro lado, también dieron un salto humano definitivo en sus vidas, pues al permitir que las vivencias interculturales con los Yagua los afecten, han entendido el sentido de la interconexión subjetiva y objetiva que liga el pensamiento indígena, el maü que conecta a los Ticuna con los Yagua, a profesores y no profesores.

Recientemente se han promovido conversaciones al interior del colegio en las que se busca escuchar más y mejor a los compañeros docentes que hacen realidad experiencias como las de la escuela de La Libertad. Desde dicha posición honesta comienza el ansiado intercambio eficiente de saberes, un horizonte distinto para la educación intercultural de su proyecto escolar.

\section{Consideraciones finales}

La descolonización de la educación escolar a partir del enfoque de la interculturalidad implica que del uso sustantivo que prima en la actualidad, se pase a la acción pedagógica, es 
decir, a la concreción de prácticas educativas que nazcan del horizonte cultural proponente. El Sistema de Educación Indígena Propia (SEIP) apoya de buena manera la formulación de proyectos educativos comunitarios e indígenas, funciona en este sentido, aunque parece que en el caso del Francisco de Orellana no se articula completamente con la práctica educativa que allí sucede. En consecuencia, el uso que el Proyecto Educativo de Macedonia ha dado a la interculturalidad es de carácter relacional y funcional, es decir que aún no aparece sistemáticamente la crítica intercultural, un ejercicio que les permitiría hacer conciencia colectiva de los momentos en que operan como una escuela del tipo enclave, hegemónica y dominante, algo que deben evitar.

Pero, aunque no aparezca sistemáticamente, las personas que intervienen y son intervenidas con el proyecto, sí actúan críticos de su interculturalidad. Probablemente tenga que ver con los modos propios de pensar de la geocultura Ticuna -fluida y extendida-, la misma que a lo largo de su historia ha asimilado la colonialidad, filosóficamente hablando, por medio de procesos de fagocitación en los que prima el "mero estar siendo" (tan propio del pensamiento indígena) en lugar del "ser alguien" (tan propio del pensamiento eurocentrado) (KUSCH, 2007). En estos momentos en que la escolaridad absorbe y es absorbida por las personas que la vivencian, se configura una escuela "injerto", una condición que deja atrás a la escuela enclave.

Basados en las encuestas, entrevistas y observaciones de tipo etnográfico que se hicieron, se fueron presentando algunos registros y reflexiones al respecto. Dichas consideraciones no encubren las contradicciones de la subjetividad, ni la inseguridad y tampoco la desconfianza. A lo mejor, en el caso de la interculturalidad como enfoque, lo adecuado sea abandonar la preocupación por adoptar posiciones fijas de verdad, para dar paso a la interpretación de la ambigüedad que la realidad plantea; es decir, admitiendo que el Estado no tiene la potestad de anticipar y cohibir los procesos independientes que se dan en las escuelas y las comunidades, y que éstas tampoco pueden escapar completamente del peso de la colonialidad del saber y poder.

Un padre de familia que cuestiona la docencia, una comunidad paralizando las actividades de su propia escuela para generar opinión regional, unos profesores que aprenden de sus estudiantes pescadores, y jóvenes que buscan sus espacios para actualizar su modo de ser, son la evidencia de la permanente critica al sistema educativo que proviene de los artífices y no del estamento regulador. Son también la constancia principal de que la falencia 
del sistema no reside en la infraestructura escolar, sino en la manera de ver la escuela y su función. Cuando prefieren verla como un enclave de occidente, las preocupaciones giran en torno a la apariencia, de si conviene tener muros (o no), de si quedarán bien los documentos (o no), en la preocupación de si funcionan (o no) los computadores. Y cuando la aceptan como un injerto, estas escuelas favorecidas por la marginalidad en que se desenvuelven ignoradas por las autoridades, crecen y se fusionan con la geocultura única y poderosa, cambiante y fluida, que acaba cultivando y rescatando las potencias de indianía que hay en los profesores, los estudiantes y los padres de familia. Se reseñaron aquí unas pocas, definitivamente hay más, muchas más.

\section{Referencias}

Asociación alemana para la educación de adultos. Reflexiones de Raúl Betancourt sobre el concepto de educación intercultural de México. (2004) Recuperado: http://www.snte.org.mx/pdfindigena/apoyo9.pdf

Brandão, Carlos R. O que é educação. São Paulo: Brasiliense. (1995)

BRITO ALARCON, Charles, Macedonia en el Amazonas: Educación Escolar indígena, interculturalidad en la frontera. Disertación de maestría Universidade Federal do Río Grande do Sul. Facultade de Educação, Porto Alegre, BR-RS, 2018

Barbosa, Cesar. El desarrollo propio en macedonia: una mirada al desarrollo indígena en la ribera amazónica colombiana. (tesis de Maestría). Universidad Nacional de Colombia, Amazonas, Colombia. (2006)

Bergamaschi, Maria Aparecida. Nhembo'e: enquanto o encanto permanece!: processos e práticas de escolarização nas aldeias Guarani. (tese de doutorado). Universidade Federal do Rio Grande do Sul. Faculdade de Educação. Porto Alegre, Brasil. (2005)

Codeba. Así construimos nuestro proyecto educativo comunitario (PEC). (2011). Recuperado de https://issuu.com/artdg/docs/amazonas_2011

Chaumeil, Jean-Pierre. Yaguas. En: Guía Etnográfica de la Alta Amazonia. Maihuna, Yagua, Ticuna.(1),181-308. (1994)

Gasché, Jorge. De hablar de educación intercultural a hacerla. Mundo Amazónico, (1) ,111134. (2010).

Kusch, Rodolfo. Esbozo para una antropología filosofía en América Latina Vol III. (241-434). Rosario: Editorial Fundación Ross. (2007). 
Kusch, Rodolfo. América Profunda. (Ed.) En Obras Completas Vol II. (9- 254). Rosario: Editorial Fundación Ross. (2007).

Mignolo, Walter. Habitar la frontera: sentir y pensar la descolonialidad. Barcelona Editorial CIDOB. (2015).

Paladino, Mariana. Experimentando a diferença -Trajetórias de jovens indígenas Tikuna em Escolas de ensino médio das cidades da Região do alto Solimões, (10), 160-181. (2010).

Panikkar, Raimond. Religión, Filosofía y Cultura. Revista de ciencias de las religiones Nro. 225-148. (1996).

Quijano, Aníbal. Colonialidad del poder, eurocentrismo y América Latina. La colonialidad del saber: eurocentrismo y ciencias sociales. Perspectivas Latinoamericanas. CLACSO ,123-151. (2000).

Walsh, Catherine. Interculturalidad crítica y educación intercultural. Ponencia Seminario "Interculturalidad y Educación Intercultural". Instituto Internacional de Integración del Convenio Andrés. La Paz. (2009).

Submetido em 27 de outubro de 2020.

Aceito em 09 de fevereiro de 2021.

Publicado em 23 de março de 2021. 